\title{
Hearing Outcome According to the Intratympanic Steroid Injection Starting Timing in Combined Intratympanic and Oral Steroid Treatment for Idiopathic Sudden Sensorineural Hearing Loss
}

\author{
Hyun Min Lee ${ }^{D}$, Da Hee Park, Dong Jo Kim, Sung Won Choi ${ }^{\mathbb{D}}$, \\ Se Joon Oh ${ }^{\mathbb{D}}$, Soo Keun Kong ${ }^{\mathbb{D}}$, and Il Woo Lee ${ }^{\mathbb{D}}$ \\ Department of Otorhinolaryngology-Head and Neck Surgery, Pusan National University College of Medicine, Yangsan, Korea
}

\author{
전신 스테로이드 및 고실 내 스테로이드 주입술 병용 요법을 이용한 특발성 돌발성 난청의 치료에서 \\ 고실 내 스테로이드 주입 시작 시기에 따른 치료 결과 \\ 이현민·박다희·김동조·최성원·오세준·공수근·이일우 \\ 부산대학교 의과대학 이비인후과학교실
}

Received May 25, 2019

Revised September 17, 2019

Accepted September 20, 2019

Address for correspondence

Il-Woo Lee, MD, PhD

Department of Otorhinolaryngology-

Head and Neck Surgery,

Pusan National University

School of Medicine,

Pusan National University

Yangsan Hospital, 20 Geumo-ro,

Mulgeum-eup, Yangsan 50612, Korea

Tel +82-55-360-2651

Fax $+82-55-360-2162$

E-mail entgate@pusan.ac.kr
Background and Objectives The combined intratympanic and oral steroid treatment has been accepted as effective treatment strategy for idiopathic sudden sensorineural hearing loss (ISSNHL). However, the treatment protocol of combined treatment for ISSNHL has not been established. In this study, we investigated whether hearing outcome differed according to different starting timing of intratympanic steroid injection (ITSI) in combined treatment for ISSNHL. Subjects and Method Tertiary academic referral center-based retrospective medical records of idiopathic 144 ISSNHL patients who received combined treatment from January 2015 to April 2018 were reviewed. All patients underwent a 2-week oral systemic steroid treatment and multiple ITSI. The hearing results of 3 months after treatment were compared according to the timing of ITSI.

Results The mean pure tone audiogram gain was $24.3 \pm 23.6 \mathrm{~dB}$. When Siegel's criteria was applied, the overall rate of hearing improvement was $63.9 \%(92 / 144)$. The rate of hearing improvement was significantly higher in women $(p=0.043)$ statistically, and there was a statistically significant lower rate of recovery in the former history of hearing loss $(p<0.01)$ or otitis media $(p<0.01)$. Moreover, the shorter the delay between symptom onset and initial ITSI, greater the statistical significance of hearing recovery rate became $(p<0.01)$.

Conclusion The result of this study suggests that early ITSI during combined intratympanic and oral steroid treatment increases the chance of hearing recovery.

Korean J Otorhinolaryngol-Head Neck Surg 2020;63(10):448-57

Key Words Hearing loss, sudden · Injection, intratympanic · Steroids.
서 론

특발성 돌발성 난청은 72 시간 이내의 시간 동안 갑작스럽게
발생하는 일측성 또는 양측성의 청력감소를 느끼는 질환으로, 청각학적으로 인접한 3곳 이상의 주파수에서 30데시벨 이상 의 청력감소가 확인되는 것으로 정의된다. ${ }^{1)}$ 특발성 돌발성 난청

This is an Open Access article distributed under the terms of the Creative Commons Attribution Non-Commercial License (https://creativecommons.org/licenses/by-nc/4.0) which permits unrestricted non-commercial use, distribution, and reproduction in any medium, provided the original work is properly cited. 
의 유병률은 1 년에 10 만 명당 5 30명인 것으로 알려져 있으 며, ${ }^{1)}$ 최근 일본의 연구에서는 10 만 명당 60.9 명의 유병률을 보인다고 하였다. ${ }^{2)}$ 특발성 돌발성 난청의 원인은 바이러스 감 염, 미세혈관 폐쇄, 청신경 종양, 자가면역 질환 등 다양한 가 설이 제시되고 있으나 정확한 기전은 아직 명확히 밝혀지지 않은 상태이다. 특발성 돌발성 난청의 치료는 현재 전신적인 고용량 스테로이드 치료가 가장 일반적으로 받아들여지고 있으며, 이외에도 항바이러스 제제, 고농도 산소 치료, 혈관 확장제 등에 의한 치료가 연구되고 있다. 또한, 치료에 실패 한 경우나 초치료로 전신 스테로이드 요법을 시행받지 못하 는 환자를 대상으로 고실 내 스테로이드 주입술을 시행하는 것을 권장하고 있다. ${ }^{1)}$ 또한 최근에는 전신 스테로이드 및 고 실 내 스테로이드 주입술 병용 요법을 시행하면 청력 회복에 도움이 된다는 결과도 보고되고 있다. ${ }^{3)}$ 저자들은 이러한 특 발성 돌발성 난청의 전신 스테로이드 및 고실 내 스테로이드 주입술 병용 요법의 치료에 있어서 치료 결과에 차이를 주는 인자를 확인하고, 고실 내 스테로이드 주입술의 시작 시기와 횟수에 따라 청력의 회복이 차이를 보이는지 확인하고자 본 연구를 진행하였다.

\section{대상 및 방법}

본 연구는 2015년 1월 2018년 4월까지 3차 의료기관 이비 인후과에 돌발성으로 발생한 일측성 또는 양측성 난청으로 입원치료를 시행한 환자 250 명을 조회하여 시작하였으며, 그 중에서 특발성 돌발성 난청의 청각학적 진단 기준을 벗어나 거나 메니에르병, 외상에 의한 난청, 뇌경색 등 중추성 질환 에 의한 난청 환자 15 명을 대상에서 제외하였다. 235 명의 환 자 중에서 68명은 전신 스테로이드 치료만을 시행받았으며 23명의 환자는 고실 내 스테로이드 주입술만을 시행받았다. 본 연구는 전신 스테로이드 및 고실 내 스테로이드 주입 병 용 요법을 시행받은 144 명의 환자들을 대상으로 후향적 의무 기록 조사를 바탕으로 이루어졌다(Fig. 1). 환자들의 의무기 록 중에서 일반적인 나이와 성별, 흡연, 음주력, 체질량지수, 현재 동반 기저 질환, 과거의 이과적 병력, 초기 동반 증상, 증상 시작일부터 치료일까지의 기간, 평균 입원 기간, 증상 시작일부터 첫 고실 내 스테로이드 주입술까지의 기간, 고실 내 스테로이드 주입 횟수, 치료 전후의 순음청력검사 결과를 수집하였다. 이 연구는 본원의 기관윤리심의위원회의 심의를 통과하였다(PNUYH IRB No. 05-2018-173).

환자들은 기본적인 병력과 청력에 대한 문진을 받았으며 함께 청력검사, 혈액검사 및 영상학적 검사를 시행받았으며, 특발성 돌발성 난청에 대한 치료는 Methylprednisolone

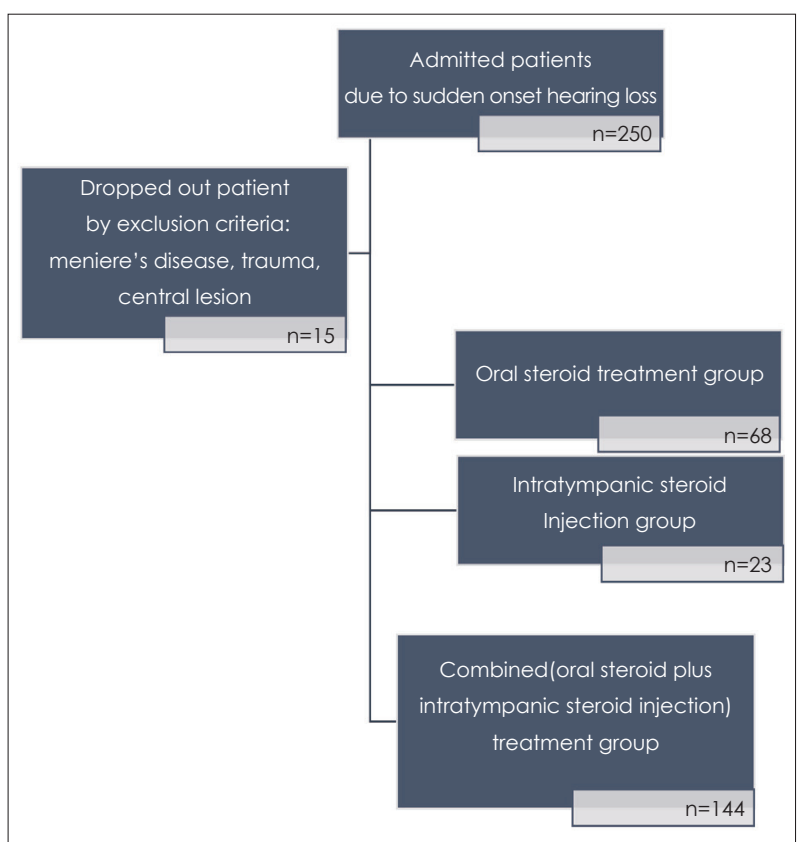

Fig. 1. Detailed number of patients by exclusion criteria and treatment option.

(Methylon ${ }^{\circledR}, 48$ mg, Alvogenkorea, Seoul, Korea)을 10일 간 사용하고 4일간 감량하여 치료하였다. 또한, Gingko biloba(Tanamin ${ }^{\circledR}, 35$ mg/10 mL, Yuyu Pharma Inc., Seoul, Korea), Lipo-Prostaglandin(Eglandin ${ }^{\circledR}, 5 \mu \mathrm{g} / \mathrm{mL}$, Mitsubishi Tanabe Pharma Korea Co., Ltd., Seoul, Korea), Carbogen $\left(95 \% \mathrm{O}_{2}+5 \% \mathrm{CO}_{2}\right)$ 흡입치료, 고실 내 스테로 이드 주입술이 동시에 시행되었다. 고실 내 스테로이드 주입 술은 과거에 중이염이 있는 환자에게서 특히 주의하여 고막 을 확인하였으며 환자의 고막 상태를 확인하여 이루, 유착 또는 천공이 있는 경우에는 시행하지 않았다, 주입술은 국소 마취제(EMLA cream ${ }^{\circledR}, 5$ g, AstraZeneca Korea, Seoul, Korea)로 10 분간 국소마취를 시행한 다음 26-gauge 척추용 주사바늘을 연결한 $1 \mathrm{cc}$ 주사기를 사용하여 미세현미경하에 서 고막 전하방에 Dexamethasone $(5 \mathrm{mg} / \mathrm{mL}$, Daewon Pharmaceutical, Seoul, Korea) 0.5 0.7 cc 범위에서 주입하 였다. 이후 최대한 약물이 고실 내에서 흡수되도록 15 분 정 도 침을 삼키거나 말하지 않고 고개를 시술한 귀의 반대쪽으 로 돌리고 앙와위에서 안정하도록 하였다. 고실 내 스테로이 드 주입술은 모든 환자에게 하루에 한 번만 시행되었고, 입 원 기간이 끝난 환자는 외래에서 필요 시 주입술을 추가로 시행하였다. 환자의 초기 난청 정도, 환자의 청력 회복 양상, 환자의 요구에 의하여 주입술의 시작 시기, 빈도(매일 또는 2 일 에 한 번)와 횟수가 결정되었다.

치료 결과의 평가를 위하여 치료 전에 순음청력검사를 시 
행하였으며 입원치료 이후 3 개월 뒤에 청력검사를 다시 시행 하여 두 결과를 비교하였다. 본 연구에서는 청력 호전 정도 를 평가하기 위하여 일반적으로 사용되는 Siegel's criteria를 사용하였다. ${ }^{4)}$ Siegel's criteria에서는 청력의 회복 크기에 상 관없이 최종 청력의 평균이 $25 \mathrm{~dB}$ 보다 양호하면 완전회복 (completely recovery), 최종 청력이 $25 \sim 45 \mathrm{~dB}$ 사이면서 청 력 회복이 $15 \mathrm{~dB}$ 보다 큰 경우에 부분회복(partial recovery), 최종 청력이 $45 \mathrm{~dB}$ 보다 나쁘면서 청력 회복이 $15 \mathrm{~dB}$ 보다 큰 경우에 경도회복(slight improvement), 최종 청력이 $75 \mathrm{~dB}$ 보다 나쁘면서 청력 회복이 $15 \mathrm{~dB}$ 보다 적은 경우에 불변(no improvement)으로 정의한다. 순음청력검사에서 청력 역치 의 평균은 $500,1000,2000,3000 \mathrm{~Hz}$ 네 주파수의 평균으로 계산하였고 치료 전과 3 개월 뒤의 청력 역치의 평균을 비교 하여 네 군으로 분류하였다. 이 중에서 다른 문헌을 참고하 여 ${ }^{5,6)}$ 완전회복, 부분회복, 경도회복 세 군을 임상적으로 의미 가 있는 청력 회복이 된 것으로 간주하였다.

통계학적 분석은 SPSS 18.0(SPSS Inc., Chicago, IL, USA) 을 통하여 시행하였으며 Student's t-test, chi-square test. Fisher's exact test, 일원배치 분산분석[one way analysis of variance(ANOVA)], 반복측정 분산분석(repeated-measures ANOVA)을 이용하였고, $p$ 값이 0.05 미만일 경우 통계적으로 유의한 의미를 가진다고 판단하였다.

\section{결 과}

총 144 명의 환자 중에서 남성은 67 명(46.5\%), 여성은 77 명 (53.5\%)이었으며, 환자들의 평균 나이는 51.85세(13 78세)였 고 남녀 모두 50대에서 환자 수가 가장 많았다. 이환된 귀는 우측, 좌측이 모두 72 귀로 동일하였다. 환자들의 나이와 성 별, 키, 체중, 체질량지수는 Table 1에 정리되어 있으며, 평균 입원 기간은 9.4일, 평균 고실 내 스테로이드 주입 횟수는 7.8 회였다. 증상 시작에서 치료 시작까지는 평균 7.5 일이 걸렸으 며 증상에서부터 첫 고실 내 스테로이드 주입술까지는 평균 9.5일이 걸렸다(Table 1).

이들 환자에서 전신 스테로이드 및 고실 내 스테로이드 주 입술 병용 요법을 시행받기 전 이환된 귀의 청력 평균은 77.0 $\pm 27.6 \mathrm{~dB}$ 이었으며 양호한 측 귀의 청력 평균은 $21.0 \pm 18.5$ $\mathrm{dB}$ 이었다. 병용 요법 치료 이후에 이환된 귀의 청력 평균은 $52.7 \pm 29.2 \mathrm{~dB}$ 로 평균 $24.3 \mathrm{~dB}$ 의 청력 호전을 보였다. 이환된 귀의 초기 청력에 따라 치료 전후의 청력 평균을 비교해 보 면, 중등고도 난청까지의 환자들은 치료 전 $50.8 \pm 14.3 \mathrm{~dB}$ 의 청력 역치를 보였고 치료 이후에는 $38.7 \pm 19.8 \mathrm{~dB}$ 의 청력역치 를 보였다. 이환된 귀의 초기 청력이 고도난청인 군에서는 치
Table 1. Clinical characteristics of sudden sensorineural hearing loss patients

\begin{tabular}{|c|c|c|c|c|}
\hline & Average & $\begin{array}{l}\text { Standard } \\
\text { deviation }\end{array}$ & Maximum & Minimum \\
\hline$\overline{\text { Age }}$ & 51.85 & 14.66 & 78 & 13 \\
\hline Height (cm) & 163.4 & 9.01 & 188 & 140 \\
\hline Weight (Kg) & 65.59 & 13.01 & 118 & 40 \\
\hline $\mathrm{BMI}\left(\mathrm{kg} / \mathrm{m}^{2}\right)$ & 24.56 & 3.77 & 36.68 & 16.23 \\
\hline $\begin{array}{l}\text { Duration of } \\
\text { admission (day) }\end{array}$ & 9.44 & 2.92 & 19 & 1 \\
\hline $\begin{array}{l}\text { Delay of Sx onset } \\
\text { to treatment (day) }\end{array}$ & 7.47 & 11.97 & 94 & 0 \\
\hline Number of ITSI & 7.83 & 3.53 & 19 & 1 \\
\hline $\begin{array}{l}\text { Delay of Sx onset } \\
\text { to ITSI (day) }\end{array}$ & 9.47 & 11.05 & 95 & 0 \\
\hline
\end{tabular}

Sx: symptom, BMI: body mass index, ITSI: intratympanic steroid injection

료 전 청력 역치의 평균이 $79.7 \pm 5.6 \mathrm{~dB}$ 을 보였으며 치료 이 후에는 $42.3 \pm 25.3 \mathrm{~dB}$ 을 보였다. 초기 청력이 전농을 보였던 환자군에서는 치료 전의 청력 역치가 $109.6 \pm 10.9 \mathrm{~dB}$ 을 보였 으며 치료 후에는 $79.7 \pm 24.3 \mathrm{~dB}$ 의 역치를 보였다(Fig. 2). 이 러한 치료 전후의 회복을 세 그룹으로 나누어 반복측정 분 산분석을 시행한 결과 세 군 모두 통계적으로 유의하게 청력 이 회복되었고 $(p<0.01)$, 각 군 간에도 청력의 회복은 통계적 으로 유의하게 차이가 있는 것으로 관찰되었다 $(p<0.01)$. Siegel's criteria를 적용하여 청력의 회복을 분류한 결과, 완 전회복을 보인 경우가 28예(19.4\%), 부분회복을 보인 경우가 41예(28.5\%), 경도회복을 보인 경우가 23예(16.0\%), 호전을 보이지 않은 경우가 52예(36.1\%)를 차지하였다. 경도회복 이 상을 청력 호전군으로 계산한 결과 전체 환자 중 $63.9 \%$ 가 회 복을 보인 것으로 나타났다(Table 2).

환자들의 일반적인 특성과 과거 병력에 따른 청력 회복을 조사한 결과 여성에서 통계적으로 유의하게 더 많은 청력 회 복이 관찰되었으며 $(p=0.043)$, 체질량지수에 따라서는 비만할 수록 회복률이 감소되었으나 통계적인 유의성은 없었다. 나 이, 흡연력, 음주력 여부는 회복률의 차이를 보이지 않았으며, 고혈압, 당뇨병, 심혈관 질환 등 과거 병력의 유무에 따라서도 회복에 차이가 없었다. 회복군과 비회복군으로 나누어 환자 의 특성을 비교한 결과 body mass index(BMI)가 통계적으 로 차이를 보였다. Siegel's criteria에 따라서 4군으로 나누어 환자의 특성을 비교한 결과 나이의 경우 완전회복군과 경도 회복군이 통계적으로 유의하게 차이가 있었으며 $(p<0.01)$, $\mathrm{BMI}$ 는 차이가 없었다(Table 2).

이전의 난청과 중이염이 있는 군에서 통계적으로 유의하게 회복률이 떨어지는 것으로 관찰되었으며 $(p<0.01, p<0.01)$, 이명과, 어지럼의 이전 이과 병력에 따라서는 환자의 회복률 

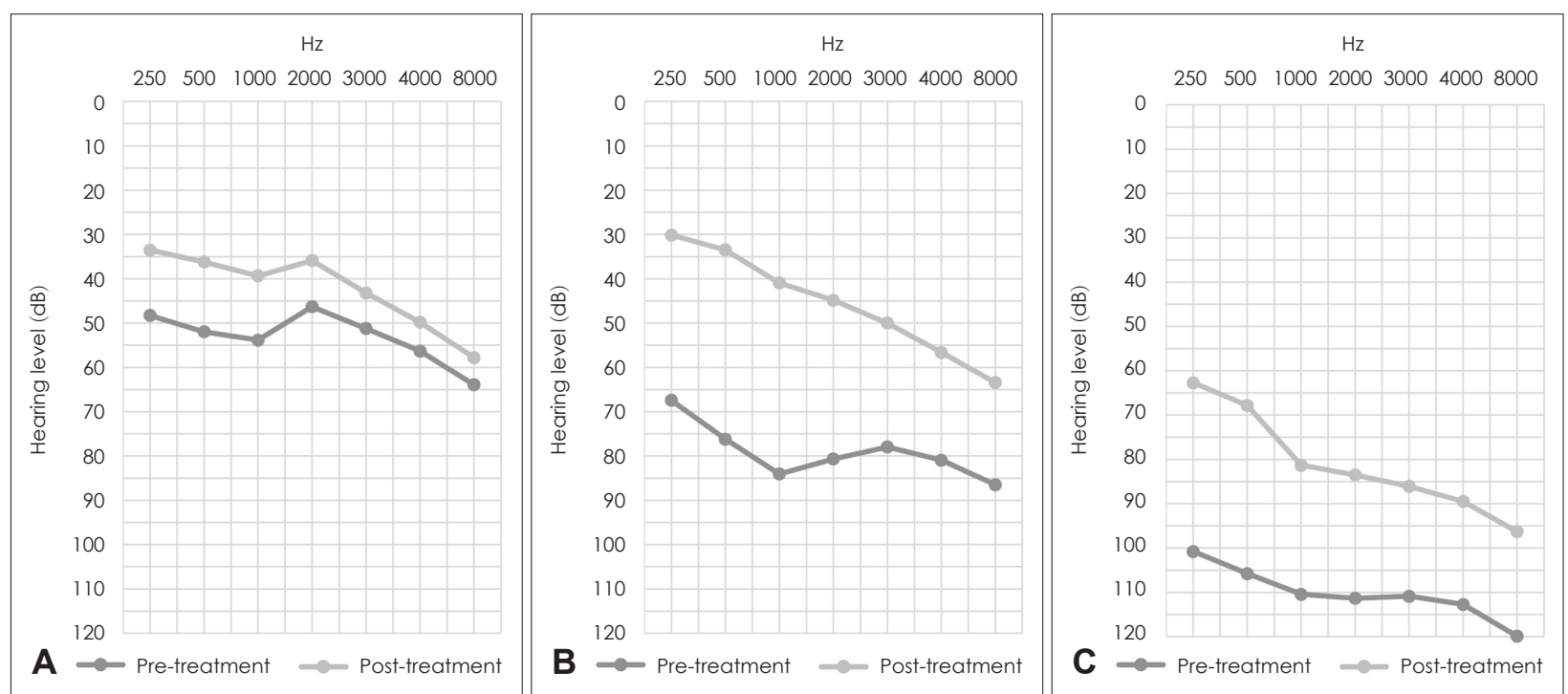

Fig. 2. Average hearing threshold of pre- and post-treatment in each group divided by initial hearing threshold of affected ear. From normal to moderately severe hearing loss group. The pre-treatment average hearing threshold of affected ear was $50.8 \pm 14.3 \mathrm{~dB}$. The average hearing threshold of the affected ear was $38.7 \pm 19.8 \mathrm{~dB}$ after the combined treatment $(\mathrm{A})$. Severe hearing loss group. The pretreatment average hearing threshold of affected ear was $79.7 \pm 5.6 \mathrm{~dB}$. The average hearing threshold of the affected ear was $42.3 \pm 25.3$ $\mathrm{dB}$ after the combined treatment (B). Profound hearing loss group. The pre-treatment average hearing threshold of affected ear was 109.6 $\pm 10.9 \mathrm{~dB}$. The average hearing threshold of the affected ear was $79.7 \pm 24.3 \mathrm{~dB}$ after the combined treatment (C).

에 차이를 보이지 않았다. 이명, 이충만감, 어지럼과 같은 특 발성 돌발성 난청과 동반된 증상의 유무에 따라서는 회복률 의 차이를 보이지 않았다. 특발성 돌발성 난청이 발생한 좌우 측에 따른 회복률의 차이는 관찰되지 않았으며, 초기 증상과 치료 시작일의 차이가 2주 이상인 경우에서 회복률이 $41.7 \%$ 로 낮았지만 치료를 2주 전에 시작한 군과 통계적으로 유의 한 회복률의 차이를 보이지는 않았다. 이환된 귀의 초기 청 력에 따라서 6 군으로 나누어 회복률의 양상을 관찰한 결과 초기 청력이 좋지 않은 군에서 회복률이 좋은 양상을 보였으 나 이는 통계적으로 유의하지는 않았으며, 따라서 이환된 귀 의 초기 청력과 Siegel's criteria를 이용하여 구한 회복률은 상관관계가 보이지 않는 것으로 관찰되었다. 회복군과 비회 복군으로 환자군을 나누어 분석한 결과, 초기 증상과 치료 시작일의 차이는 각 군에 따른 차이를 보이지 않았으나, 이 환 된 귀의 초기 청력은 회복군에서 더 좋지 않았던 것으로 분석되었다 $(p<0.01)$. Siegel's criteria에 따라 4 군으로 환자 군을 나누어 분석한 결과, 초기 증상과 치료 시작일의 차이 는 각 군에 따른 차이를 보이지 않았으나, 이환된 귀의 초기 청력은 각 군마다 차이를 보였으며 특히 경도회복군이 다른 군보다 초기 청력이 좋지 않았다 $(p<0.01)$ (Table 3).

고실 내 스테로이드 주입술의 횟수와 청력의 회복 여부를 비교한 결과 주입술의 횟수와 회복률의 차이는 연관성을 보 이지 않았다. 하지만 고실 내 스테로이드 주입술의 시작 시기 와 회복률의 연관성을 조사하였을 때, 증상 시작일에서 7일
이전에 주입술을 시작한 경우가 회복률이 $75 \%, 8$ 일 2주 사 이에 시작한 경우가 $54.3 \%, 2$ 주 이후 시작한 경우가 $45.5 \%$ 로 주입술을 빨리 시작할수록 통계적으로 유의하게 높은 회복 률을 보였다 $(p=0.003)$ (Fig. 3). 회복군과 비회복군으로 환자 군을 나누어 분석한 결과, 고실 내 스테로이드 주입술의 횟 수는 두 군 사이에 차이를 보이지 않았으며, 고실 내 스테로 이드 주입술의 시작 시기는 회복군에서 더 빨랐던 것으로 분 석되었다 $(p=0.017)$. Siegel's criteria에 따라 4군으로 환자군 을 나누어 분석한 결과, 고실 내 스테로이드 주입술의 횟수 는 경도회복군에서 통계적으로 유의하게 다른 군들보다 높 았으며 $(p<0.01)$, 고실 내 스테로이드 주입술의 시작 시기는 네 군이 통계적으로 유의한 차이를 보이지 않았다.

\section{고 찰}

특발성 돌발성 난청의 치료에 있어서 전신 스테로이드 치료 는 일반적인 방법으로 받아들여지고 사용되고 있다. 하지만 일부 리뷰에서는 잘 설계된 이중맹검 위약 사용 연구가 부족 하여 스테로이드의 사용이 과학적 증거가 부족하다는 결론 을 제시하고 있다. ${ }^{78)}$ 또한, 전신상태 불량이나 당뇨병과 같이 전신 스테로이드 투여가 불가능한 경우나 초기 전신 스테로 이드 치료가 실패한 경우에는 적절한 치료 방법이 없었다. 이 러한 제한점을 극복하기 위하여, 고실 내 스테로이드 주입술 은 1996년에 처음 Silverstein 등'에 의하여 보고되었는데, 
Korean J Otorhinolaryngol-Head Neck Surg I 2020;63(10):448-57

Table 2. Hearing recovery result according to the patient demographics and combined disease

\begin{tabular}{|c|c|c|c|c|c|c|c|c|}
\hline & $\begin{array}{l}\text { Complete } \\
\text { recovery }\end{array}$ & $\begin{array}{l}\text { Partial } \\
\text { recovery }\end{array}$ & $\begin{array}{c}\text { Slight } \\
\text { recovery }\end{array}$ & Recover & $\begin{array}{c}\text { No } \\
\text { improvement }\end{array}$ & Total (\%) & $\begin{array}{l}\text { Recovery } \\
\text { rate }(\%)\end{array}$ & p-value \\
\hline Total hearing result & 28 & 41 & 23 & 92 & 52 & $144(100)$ & 63.9 & \\
\hline \multicolumn{9}{|l|}{ Sex } \\
\hline Male & 8 & 10 & 19 & 37 & 30 & $67(46.5)$ & 55.2 & \multirow{2}{*}{0.043} \\
\hline Female & 20 & 13 & 22 & 55 & 22 & $77(53.5)$ & 71.4 & \\
\hline \multicolumn{9}{|l|}{ Age group } \\
\hline Average & $44.07 \pm 15.72$ & $53.65 \pm 13.79$ & $56.63 \pm 11.05$ & $52.07 \pm 14.37$ & $51.48 \pm 15.15$ & $51.85 \pm 14.66$ & & $\begin{array}{l}0.820 \\
0.005^{*}\end{array}$ \\
\hline$<20$ & 3 & 1 & 0 & 4 & 4 & $8(5.6)$ & 50.0 & \multirow{4}{*}{0.868} \\
\hline $20-40$ & 9 & 3 & 5 & 17 & 7 & $24(16.7)$ & 70.8 & \\
\hline $40-60$ & 11 & 11 & 20 & 42 & 25 & $67(46.5)$ & 62.7 & \\
\hline$>60$ & 5 & 8 & 16 & 29 & 16 & $45(31.3)$ & 64.4 & \\
\hline \multicolumn{9}{|c|}{ BMI (World Health Organization classification) } \\
\hline Average & $23.63 \pm 3.70$ & $24.07 \pm 3.83$ & $24.36 \pm 3.91$ & $24.07 \pm 3.84$ & $25.43 \pm 3.49$ & $24.56 \pm 3.77$ & & $\begin{array}{l}0.038 \\
0.180^{*}\end{array}$ \\
\hline Normal $(<25)$ & 19 & 15 & 24 & 58 & 24 & $82(56.9)$ & 70.7 & \multirow[t]{3}{*}{0.051} \\
\hline Overweight $(25-30)$ & 8 & 5 & 15 & 28 & 22 & $50(34.7)$ & 56.0 & \\
\hline Obese $(>30)$ & 1 & 3 & 2 & 6 & 6 & $12(8.3)$ & 50.0 & \\
\hline \multicolumn{9}{|l|}{ Alcohol drink } \\
\hline Yes & 7 & 5 & 12 & 24 & 13 & $37(25.7)$ & 64.9 & \multirow{2}{*}{0.886} \\
\hline No & 21 & 18 & 29 & 68 & 39 & $107(74.3)$ & 63.6 & \\
\hline \multicolumn{9}{|l|}{ Smoke } \\
\hline Yes & 4 & 2 & 5 & 11 & 9 & $20(13.9)$ & 55.0 & \multirow{3}{*}{0.443} \\
\hline No & 24 & 21 & 33 & 78 & 40 & 118 (81.9) & 66.1 & \\
\hline Former & 0 & 0 & 3 & 3 & 3 & $6(4.2)$ & 63.9 & \\
\hline \multicolumn{9}{|l|}{ Combined disease } \\
\hline \multicolumn{9}{|l|}{ Hypertension } \\
\hline Yes & 6 & 3 & 21 & 30 & 12 & $42(29.2)$ & 71.4 & \multirow{2}{*}{0.227} \\
\hline No & 22 & 20 & 20 & 62 & 40 & $102(70.8)$ & 60.8 & \\
\hline \multicolumn{9}{|l|}{ Diabetes } \\
\hline Yes & 3 & 3 & 9 & 15 & 5 & $20(13.9)$ & 75.0 & \multirow{2}{*}{0.265} \\
\hline No & 25 & 20 & 32 & 77 & 47 & $124(86.1)$ & 62.1 & \\
\hline \multicolumn{9}{|l|}{ Heart disease } \\
\hline Yes & 0 & 0 & 4 & 4 & 2 & $6(4.2)$ & 66.7 & \multirow{2}{*}{1.000} \\
\hline No & 28 & 23 & 37 & 88 & 50 & $138(96.8)$ & 63.8 & \\
\hline
\end{tabular}

Values are presented as number or mean \pm standard deviation. *by one way analysis of variance according to 4 group of Siegel's criteria. BMl: body mass index

많은 연구에서 구제 요법이나 전신 스테로이드를 사용하지 못하는 경우에 대안적인 치료 방법으로 청력 호전에 효과가 있다고 보고되고 있다. ${ }^{10,11)}$ 또한, ITSI 단독 요법은 전신 스테 로이드 치료와 통계적으로 차이가 나지 않는 치료 효과를 보 였으며, 전신 스테로이드의 부작용이 적었다는 리뷰 문헌이 있었고, ${ }^{12)}$ 다른 리뷰 문헌들에서는 과학적인 이중맹검법을 사 용한 대규모의 연구가 적고 주사 방법의 표준안이 통일되어 있지 않아서 효과를 증명할 수 없다는 발표도 있었다. ${ }^{13,14)}$

이러한 제한점을 극복하기 위하여 이전부터 전신 스테로이 드 치료와 고실 내 스테로이드 주입술을 초치료로 동시에 시
행하는 병용 요법에 대한 연구가 이루어져 왔다. 대한민국에 서 시행된 고도 및 심도 특발성 돌발성 난청에 대한 병용 요법 의 효과에 대한 보고에서는 전신 스테로이드 치료에 비하여 병용 요법이 통계적으로 유의하게 청력을 호전시키는 것으로 보고되었다. ${ }^{5)}$ 또한 다른 연구에서는 147 명의 특발성 돌발성 난청 환자를 대상으로 병용 요법을 시행하였으며 그 중 91명 (61.9\%)이 회복이 되었다고 하였다. ${ }^{6}$ 특발성 돌발성 난청 치료 방법에 대한 다기관 이중맹검 위약 사용 연구에서는 병용요법 을 사용한 경우에서 전신 스테로이드 치료와 고실 내 스테로 이드 주입술을 별도로 시행한 군보다도 더 신속하게 회복되 
Table 3. Hearing recovery result according to the otologic symptom and history

\begin{tabular}{|c|c|c|c|c|c|c|c|c|}
\hline & $\begin{array}{l}\text { Complete } \\
\text { recovery }\end{array}$ & $\begin{array}{l}\text { Partial } \\
\text { recovery }\end{array}$ & $\begin{array}{l}\text { Slight } \\
\text { recovery }\end{array}$ & Recover & $\begin{array}{c}\text { No } \\
\text { improvement }\end{array}$ & Total (\%) & $\begin{array}{l}\text { Recovery } \\
\text { rate }(\%)\end{array}$ & p-value \\
\hline \multicolumn{9}{|l|}{ Former otologic history } \\
\hline \multicolumn{9}{|l|}{ Hearing loss } \\
\hline Yes & 1 & 8 & 9 & 18 & 24 & $42(29.2)$ & 42.9 & \multirow{2}{*}{0.001} \\
\hline No & 27 & 15 & 32 & 74 & 28 & $102(70.8)$ & 72.5 & \\
\hline \multicolumn{9}{|l|}{ Chronic otitis media } \\
\hline Yes & 1 & 0 & 0 & 1 & 6 & $7(4.9)$ & 14.3 & \multirow{2}{*}{0.009} \\
\hline No & 27 & 23 & 41 & 91 & 46 & $137(95.1)$ & 66.4 & \\
\hline \multicolumn{9}{|l|}{ Tinnitus } \\
\hline Yes & 1 & 3 & 1 & 5 & 7 & $12(8.3)$ & 41.7 & \multirow{2}{*}{0.119} \\
\hline No & 27 & 20 & 40 & 87 & 45 & $132(91.7)$ & 65.9 & \\
\hline \multicolumn{9}{|l|}{ Dizziness } \\
\hline Yes & 0 & 0 & 3 & 3 & 4 & $7(4.9)$ & 42.9 & \multirow{2}{*}{0.253} \\
\hline No & 28 & 23 & 38 & 89 & 48 & $137(95.1)$ & 65.0 & \\
\hline \multicolumn{9}{|c|}{ Combined otologic symptom } \\
\hline \multicolumn{9}{|l|}{ Tinnitus } \\
\hline Yes & 24 & 17 & 26 & 67 & 39 & $106(73.6)$ & 63.2 & \multirow{2}{*}{0.776} \\
\hline No & 4 & 6 & 15 & 25 & 13 & $38(26.4)$ & 65.8 & \\
\hline \multicolumn{9}{|l|}{ Fullness } \\
\hline Yes & 18 & 11 & 17 & 46 & 20 & $66(45.8)$ & 69.7 & \multirow{2}{*}{0.182} \\
\hline No & 10 & 12 & 24 & 46 & 32 & $78(54.2)$ & 59.0 & \\
\hline \multicolumn{9}{|l|}{ Dizziness } \\
\hline Yes & 3 & 5 & 24 & 32 & 19 & $51(35.4)$ & 62.7 & \multirow{2}{*}{0.832} \\
\hline No & 25 & 18 & 17 & 60 & 33 & $93(64.6)$ & 64.5 & \\
\hline \multicolumn{9}{|l|}{ Laterality } \\
\hline Right ear & 13 & 10 & 21 & 44 & 28 & $72(50.0)$ & 61.1 & \multirow{2}{*}{0.488} \\
\hline Left ear & 15 & 13 & 20 & 48 & 24 & $72(50.0)$ & 66.7 & \\
\hline \multicolumn{9}{|c|}{ Delay of symptom onset to treatment (days) } \\
\hline Average & $5.71 \pm 4.72$ & $8.48 \pm 15.2$ & $5.76 \pm 9.94$ & $6.42 \pm 10.48$ & $9.31 \pm 14.05$ & $7.47 \pm 11.97$ & & $\begin{array}{l}0.167 \\
0.425^{*}\end{array}$ \\
\hline$\leq 7$ & 18 & 16 & 29 & 63 & 33 & $96(66.7)$ & 65.6 & \multirow{3}{*}{0.242} \\
\hline $8-14$ & 9 & 5 & 10 & 24 & 12 & $36(25.0)$ & 66.7 & \\
\hline$\geq 15$ & 1 & 2 & 2 & 5 & 7 & $12(8.3)$ & 41.7 & \\
\hline \multicolumn{9}{|c|}{ Initial hearing level of affected side } \\
\hline Average & $60.22 \pm 20.85$ & $72.88 \pm 14.38$ & $104.79 \pm 14.43$ & $83.25 \pm 25.92$ & $66.03 \pm 27.07$ & $77.03 \pm 27.61$ & & $\begin{array}{l}<0.001 \\
<0.001^{*}\end{array}$ \\
\hline Normal & 2 & 0 & 0 & 2 & 2 & $4(2.8)$ & 50.0 & \multirow{6}{*}{0.056} \\
\hline Mild & 2 & 0 & 0 & 2 & 5 & $7(4.9)$ & 28.6 & \\
\hline Moderate & 8 & 3 & 0 & 11 & 11 & $22(15.3)$ & 50 & \\
\hline Moderately severe & 3 & 8 & 1 & 12 & 16 & $28(19.4)$ & 42.9 & \\
\hline Severe & 13 & 8 & 7 & 28 & 9 & $37(25.7)$ & 75.7 & \\
\hline Profound & 0 & 4 & 33 & 37 & 9 & $46(31.9)$ & 80.4 & \\
\hline Number of ITSI & $6.29 \pm 2.25$ & $7.00 \pm 2.48$ & $9.68 \pm 4.03$ & $7.98 \pm 3.57$ & $7.58 \pm 3.47$ & $7.83 \pm 3.53$ & & $\begin{array}{l}0.516 \\
0.001^{*}\end{array}$ \\
\hline $\begin{array}{l}\text { Delay of symptom } \\
\text { onset to ITSI (days) }\end{array}$ & $6.71 \pm 4.7$ & $9.43 \pm 6.83$ & $7.68 \pm 10.81$ & $7.83 \pm 8.45$ & $12.38 \pm 14.09$ & $9.47 \pm 11.05$ & & $\begin{array}{l}0.017 \\
0.093^{*}\end{array}$ \\
\hline
\end{tabular}



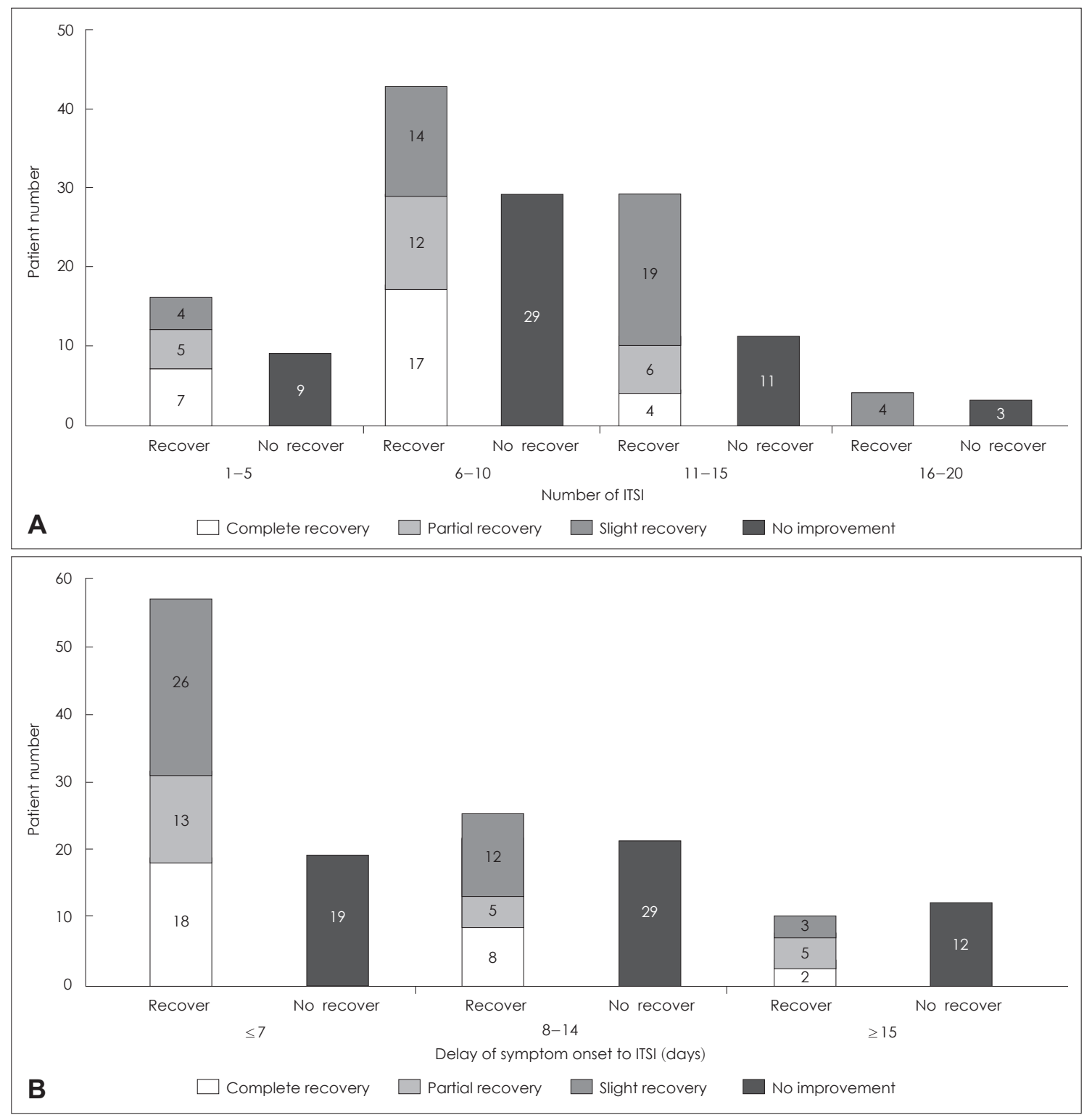

Fig. 3. Hearing outcome according to number of ITSI (A). Hearing outcome according to delay of symptom onset to ITSI (B). Number of ITSI and recovery rate were not significantly related. Shorter delay of symptom onset to ITSI showed a statistically significant improvement in recovery rate $(p=0.003)$. ITSI: intratympanic steroid injection.

고 어음명료도와 순음청력검사상 청력 역치가 더 많이 호전 되는 양상을 보였다. ${ }^{15)}$ 같은 연구자가 시행한 다른 연구에서 도 병용 요법은 전신 스테로이드 치료법에 비하여 청력 역치 와 어음명료도를 더 많이 호전시키는 것으로 나타났다. 또한, 증상 발생으로부터 7일 이전에 치료를 한 경우에 호전이 더 많이 되는 것으로 나타났다. ${ }^{16)}$ 병용 요법에 대한 리뷰 문헌에 서는 문헌에 따라 스테로이드 주입 용량이나 주입 횟수, 청력 회복에 대한 정의가 다르다는 제한점이 있으나 전신 스테로이 드 치료보다는 병용 요법이 더 효과가 있는 것으로 보인다고 하였다. ${ }^{3)}$ 이 같은 결과는 다양하게 해석할 수 있겠으나, 전신
스테로이드 치료에 고실 내 스테로이드 주입술을 더함으로써 외림프액에 더 고농도의 스테로이드를 전달할 수 있고 이를 통해 와우에 스테로이드 전달을 더 많이 하여 유모세포 자멸 사의 시작을 막고, 염증을 줄이고 내림프계의 항상성을 안정 화시켜 나선신경절(spiral ganglion)에서 Corti 기관으로의 혈 류 전달을 재개하여 추가적인 치료 효과를 얻을 수 있다고 하 는 가설이 널리 받아들여지고 있다. ${ }^{3)}$

이와 반대로 병용 요법은 다른 치료법과 비교하여 별다른 추가적 이득이 없다는 보고도 있었는데, 735 명의 특발성 돌 발성 난청 환자를 전신 스테로이드 치료, 고실 내 스테로이드 
주입, 병용 요법 3군으로 나누어 치료를 하고 결과를 보고한 연구에서는 3군은 치료에 있어 통계적으로 유의한 차이가 없 다고 하였다. ${ }^{17)} 3$ 군으로 특발성 돌발성 난청 환자를 치료한 결과에 대한 연구에서는 병용 요법에서 가장 높은 청력 향상 이 있긴 하였으나 청력 회복에는 통계적인 차이가 없었다고 보고하였다. ${ }^{18)} 120$ 명의 특발성 돌발성 난청 환자를 대상으로 한 비교 연구에서 병용 요법은 전신 스테로이드 치료법 단독 으로 사용하는 것에 비하여 유의한 이득을 보이지 않았으나, $250 \mathrm{~Hz}$ 영역의 청력만이 통계적으로 유의하게 호전에 도움 이 된다고 보고하였다. ${ }^{19)}$ 또한, 일부 연구에서는 병용 요법이 시행될 경우 고실 내 스테로이드 주사로 인하여 고막천공과 중이염, 일시적 어지럼, 이통 등 전신 스테로이드 치료에는 보 이지 않는 부작용을 가진다고 보고하였다. ${ }^{20)}$ 이러한 병용 요 법의 효과에 대한 연구 간의 차이는 다양한 해석이 가능하 겠으나, Battaglia 등 ${ }^{16)}$ 의 연구와 같이 효과가 있다고 보고된 연구에서는 Ahn 등 ${ }^{19)}$ 의 연구에서와 같이 효과가 없었다고 하는 연구보다도 주입된 스테로이드의 함량이 높았다. 이와 같은 연구 간의 치료 방법 차이와 환자군의 차이가 치료 결 과의 차이를 유발하는 원인이 될 것으로 생각된다. ${ }^{3)}$

본 연구에서는 여성인 경우에 치료 효과가 높았으며 고실 내 스테로이드 주입술을 빨리 시행한 경우에 더 많은 호전을 보였다. 또한 초기 청력이 나쁠수록 호전이 더 잘되는 경향 이 나타났는데 이 경우에는 초기 청력이 심도 난청인 경우 회복의 대부분은 경도회복이었기 때문에 이에 대한 고려가 필요하다. 이전의 난청이나 만성 중이염이 있었던 경우에는 통계적으로 유의하게 잘 회복되지 않는 경향이 나타났다.

성별에 따라 특발성 돌발성 난청의 회복이 차이가 있는가 에 대해서는 다양한 보고가 존재하는데 특발성 돌발성 난청 의 치료에서 성별은 예후 인자가 되지 못한다는 결과를 주로 보였으나 ${ }^{1,6)}$ 스테로이드와 prostaglandin을 병용치료한 그룹 에서 여성인 경우 치료 예후가 더 좋았다는 보고가 있었다. ${ }^{21)}$ 이전 이과적 병력 또는 동반되는 이과적 증상이 특발성 돌발 성 난청의 예후와 연관이 있는가에 대해서는 이견이 존재하 는데, 동반되는 현훈이 특발성 돌발성 난청의 부정적인 예후 와 연관이 있다는 보고가 일부 있으나리 본 연구와 같이 중 이염, 난청의 병력이 부정적인 예후와 연관된다는 보고는 없 었다. 다만 유일청이(only hearing ear)에서 발생한 특발성 돌발성 난청의 경우 회복률이 낮다는 일부 보고가 있었다. ${ }^{23)}$

성별과 이전의 만성 중이염, 난청 병력의 유무에 따라 특발 성 돌발성 난청의 병용 요법 치료 예후가 차이가 있었는데, 이러한 요소와 고실 내 스테로이드 주입술의 횟수와 시작 시 기에 차이가 있는지를 분석하였다. 각 요소의 차이에 따라 주입술의 횟수는 차이가 있지 않았으나, 남성의 경우에서 통
Table 4. Relationship between sex, former history of hearing loss, chronic otitis media with number of intratympanic steroid injection, and delay of symptom onset to intratympanic steroid injection

\begin{tabular}{lcc}
\hline & Number of ITSI & Delay of symptom onset to ITSI \\
\hline Male & $7.51 \pm 3.73$ & $11.48 \pm 14.35$ \\
Female & $8.12 \pm 3.38$ & $7.73 \pm 6.79$ \\
p-value & 0.306 & 0.043 \\
COM (-) & $7.85 \pm 3.56$ & $9.36 \pm 11.23$ \\
COM (+) & $7.43 \pm 3.51$ & $11.57 \pm 8.24$ \\
p-value & 0.723 & 0.321 \\
HL (-) & $7.98 \pm 3.52$ & $9.59 \pm 11.16$ \\
HL (+) & $7.48 \pm 3.63$ & $9.19 \pm 11.05$ \\
p-value & 0.440 & 0.846
\end{tabular}

Values are presented as mean \pm standard deviation. ITSI: intratympanic steroid injection, COM: chronic otitis media, $\mathrm{HL}$ : hearing loss

계적으로 유의하게 주입술의 시작일수가 늦었다 $(p=0.043)$ (Table 4). 남성의 경우 특발성 돌발성 난청의 증상 시작일로 부터 전체적인 입원치료의 시작일까지의 기간이 평균 9.37일 로 여성의 5.81일보다 통계적으로 유지하진 않으나 늦은 경 향을 보였다 $(p=0.075)$.

병용 요법에 대한 예후 인자에 대한 기존 연구에서, 단변 량 분석(univariative analysis)상으로 나이, 청력도의 패턴, 이명 여부가 예후 인자였다. 특히 청력도에서 down-sloping 또는 농인 환자에서 청력 회복이 잘 안 되는 경향을 보였다. ${ }^{6}$ Kang 등 ${ }^{24)}$ 은 494 명의 특발성 돌발성 난청 환자의 치료 예후 에 대하여 연구하였는데, 단변량 분석에서는 나이, 당뇨와 고지질혈증의 유무, 어지럼 증상의 유무, 증상 시작일부터 치 료일까지의 기간, 초기 청력 역치와 어음명료도, 치료 방법, 증상과 고실 내 스테로이드 주입술 시작까지의 기간 등이 예 후 인자로 확인되었다. 해당 연구에서는 병용 요법보다는 경 구 스테로이드를 사용한 뒤에 고실 내 스테로이드 주입술을 시행하는 것이 가장 좋은 예후를 보인다고 하였다.

본 연구에서는 병용 요법 치료에서 고실 내 스테로이드 주 입술이 빠를수록 더 높은 회복률을 보였고 주입술의 횟수는 예후와 상관이 없었다. 고실 내 스테로이드 주입술의 시기와 횟수에 따른 치료 결과에 대해서는 몇 가지 연구가 기존에 시행되었다. Park 등 ${ }^{25)}$ 은 98명의 특발성 돌발성 난청 환자를 대상으로 고실 내 스테로이드 주입술을 시행한 결과 경구 스 테로이드 치료의 여부와 상관없이 증상 발생 후 10 일 이내에 주입술을 시행하였을 때 가장 높은 호전율을 보였다고 보고 하였다. 191 명의 특발성 돌발성 난청 환자에 대하여 병용 요 법을 시행한 연구에서는 고실 내 스테로이드 주입술을 2회와 4회로 나누어서 시행한 치료 결과를 보고하였는데, 그 결과 주입술의 횟수에 따른 치료 결과 차이는 없다고 보고하였 다. ${ }^{26)}$ Sugihara 등 ${ }^{27)}$ 은 고실 내 스테로이드 주입술의 빈도 차 
이는 치료 결과의 차이를 보이지 않았지만 증상 시작일로부 터 빨리 시작될수록 청력 회복이 더 잘되는 경향을 보였다고 보고하였다. 이러한 결과들은 본 연구의 결과와 유사하였으 며, 병용 요법에서 고실 내 주입술을 증상 시작 이후 빨리 시 작하는 것이 더 나은 치료 결과를 보일 수 있어 치료에 고려 되어야 하겠으며, 주입술의 횟수는 예후와 상관이 없고 횟수 가 증가할수록 고막천공이나 통증 등 부작용이 발생할 개연 성이 높아지므로 너무 많은 주입술은 지양되어야 할 것으로 생각된다.

하지만 기존 연구 중 특발성 돌발성 난청에 대한 치료가 시행된 이후 고실 내 스테로이드 주입술을 구제요법으로 사 용하는 것이 추천된다는 최신 임상진료지침이 발간되었고, ${ }^{1)}$ 고실 내 스테로이드 주입술을 구제 요법으로 시행한다면 회 복이 더 잘된다는 보고와, ${ }^{28,29)}$ 구제 요법이 효과적이지 않다 는 보고도 있다. ${ }^{30)}$ 이러한 부분은 본 연구에서 고실 내 스테 로이드 주입술의 횟수와 청력의 회복이 상관이 없었다는 본 연구 결과와 차이가 있어서 이에 대해서는 추가적인 연구가 필요한 실정이다.

본 연구는 몇 가지 한계점을 가진다. 우선, 본 연구는 후향 적 의무기록을 바탕으로 한 연구로, 대조군이 없고, 무작위 위약 연구가 시행되지 않아 그 해석에 있어 다양한 오류가 존재할 수 있다는 한계를 가진다. 또한 본 연구에서는 Siegel's criteria을 기준으로 경도회복 이상을 청력 회복군으로 처리 하였는데, 기존에 이러한 기준으로 진행된 연구가 있었지만 본 연구에서는 청력 회복이 너무 과대평가되었을 수 있다는 점이 고려되어야 하겠다. 또한 치료의 결과를 순음청력검사 역치만을 고려하였는데 치료 전후의 어음명료도 차이가 분 석되지 않아 환자의 청력을 평가하는 데 제한점이 있을 것으로 판단된다. 또한 본 연구들의 대상 환자들은 1 회에서 총 19 회 까지 다양한 범위의 고실 내 스테로이드 주입술을 시행받았 는데 시술 이후 고막의 지속적 천공이나 이루 및 이통 등 부 작용에 대한 분석이 이루어지지 않아 고실 내 스테로이드 주 입술에 대한 이득과 손실에 대한 정확한 평가를 할 수 없었 던 것도 한계로 생각된다.

전신 스테로이드 및 고실 내 스테로이드 병용 요법은 특발 성 돌발성 난청을 치료하는 데에 있어 효과적인 방법이다. 또 한 병용 요법을 시행할 경우 고실 내 스테로이드 주입술의 횟 수는 치료 성공과 관련이 있지 않았으나, 조기에 고실 내 스 테로이드 주입술을 시행하는 것이 더 좋은 예후를 보여 향후 치료에서 이를 반영하여 병용 요법을 시행할 경우 조기에 고 실 내 스테로이드 주입술 치료를 시작하는 것이 좀 더 좋은 치료 효과를 가져오는 방법이라 할 수 있겠다.

\section{Acknowledgments}

This study was supported by a 2019 research grant from Pusan National University Yangsan Hospital. The authors declare that they have no conflict of interest.

\section{Author Contribution}

Conceptualization: Hyun Min Lee, Soo Keun Kong, Il Woo Lee. Data curation: Hyun Min Lee, Da Hee Park, Dong Jo Kim. Formal analysis: Hyun Min Lee, Da Hee Park, Dong Jo Kim. Funding acquisition: Hyun Min Lee. Investigation: Da Hee Park, Dong Jo Kim. Methodology: Hyun Min Lee, Sung Won Choi. Project administration: Hyun Min Lee, Il Woo Lee. Resources: Hyun Min Lee, Il Woo Lee. Software: Hyun Min Lee. Supervision: Soo Keun Kong, Il Woo Lee. Validation: Sung Won Choi, Se Joon Oh. Visualization: Hyun Min Lee. Writing — original draft: Hyun Min Lee. Writingreview \& editing: Hyun Min Lee, Il Woo Lee.

\section{ORCIDs}

Il Woo Lee

Hyun Min Lee

https://orcid.org/0000-0001-9561-6585

Sung Won Choi

Se Joon Oh

Soo Keun Kong https://orcid.org/0000-0001-6306-5256 https://orcid.org/0000-0002-7463-7720 https://orcid.org/0000-0001-8910-0064 https://orcid.org/0000-0002-6783-3766

\section{REFERENCES}

1) Chandrasekhar SS, Tsai Do BS, Schwartz SR, Bontempo LJ, Faucett EA, Finestone SA, et al. Clinical practice guideline: Sudden hearing loss (Update). Otolaryngol Head Neck Surg 2019;161(1 Suppl):S1-45.

2) Nakashima T, Sato H, Gyo K, Hato N, Yoshida T, Shimono M, et al. Idiopathic sudden sensorineural hearing loss in Japan. Acta Otolaryngol 2014;134(11):1158-63.

3) Han $X$, Yin X, Du X, Sun C. Combined intratympanic and systemic use of steroids as a first-line treatment for sudden sensorineural hearing loss: A meta-analysis of randomized, controlled trials. Otol Neurotol 2017;38(4):487-95.

4) Siegel LG. The treatment of idiopathic sudden sensorineural hearing loss. Otolaryngol Clin North Am 1975;8(2):467-73.

5) Kim SH. The effects of combined intratympanic and oral steroid treatment for severe to profound sudden sensorineural hearing loss. J Clinical Otolaryngol 2016;27(1):76-83.

6) Baek MK, Cho CH, Bang YJ, Oh NR, Baek MJ, Lee JH. Hearing outcomes and prognostic factors in idiopathic sudden sensorineural hearing loss patients with combined intratympanic and systemic steroid therapy. Korean J Otorhinolaryngol-Head Neck Surg 2018;61(5):242-6.

7) Wei BP, Stathopoulos D, O'Leary S. Steroids for idiopathic sudden sensorineural hearing loss. Cochrane Database Syst Rev 2013;(7): CD003998.

8) Lawrence R, Thevasagayam R. Controversies in the management of sudden sensorineural hearing loss: An evidence-based review. Clin Otolaryngol 2015;40(3):176-82.

9) Silverstein H, Choo D, Rosenberg SI, Kuhn J, Seidman M, Stein I. Intratympanic steroid treatment of inner ear disease and tinnitus (preliminary report). Ear Nose Throat J 1996;75(8):468-71.

10) Ho HG, Lin HC, Shu MT, Yang CC, Tsai HT. Effectiveness of intratympanic dexamethasone injection in sudden-deafness patients as salvage treatment. Laryngoscope 2004;114(7):1184-9.

11) Jung JH, Kim, MS, Kim, DJ, Lee IW. Salvage treatment of sudden sensorineural hearing loss. J Clinical Otolaryngol 2017;28(1):49-52.

12) Lai D, Zhao F, Jalal N, Zheng Y. Intratympanic glucocorticosteroid 
therapy for idiopathic sudden hearing loss: Meta-analysis of randomized controlled trials. Medicine (Baltimore) 2017;96(50):e8955.

13) Lavigne P, Lavigne F, Saliba I. Intratympanic corticosteroids injections: A systematic review of literature. Eur Arch Otorhinolaryngol 2016;273 (9):2271-8.

14) El Sabbagh NG, Sewitch MJ, Bezdjian A, Daniel SJ. Intratympanic dexamethasone in sudden sensorineural hearing loss: A systematic review and meta-analysis. Laryngoscope 2017;127(8):1897-908.

15) Battaglia A, Burchette R, Cueva R. Combination therapy (intratympanic dexamethasone+high-dose prednisone taper) for the treatment of idiopathic sudden sensorineural hearing loss. Otol Neurotol 2008;29(4):453-60.

16) Battaglia A, Lualhati A, Lin H, Burchette R, Cueva R. A prospective, multi-centered study of the treatment of idiopathic sudden sensorineural hearing loss with combination therapy versus high-dose prednisone alone: A 139 patient follow-up. Otol Neurotol 2014;35(6):1091-8.

17) Bae SC, Noh HI, Jun BC, Jeon EJ, Seo JH, Park SY, et al. Efficacy of intratympanic steroid therapy for idiopathic sudden sensorineural hearing loss: Comparison with systemic steroid therapy and combined therapy. Acta Otolaryngol 2013;133(5):428-33.

18) Lim HJ, Kim YT, Choi SJ, Lee JB, Park HY, Park K, et al. Efficacy of 3 different steroid treatments for sudden sensorineural hearing loss: A prospective, randomized trial. Otolaryngol Head Neck Surg 2013;148(1):121-7.

19) Ahn JH, Yoo MH, Yoon TH, Chung JW. Can intratympanic dexamethasone added to systemic steroids improve hearing outcome in patients with sudden deafness? Laryngoscope 2008;118(2):279-82.

20) Koltsidopoulos P, Bibas A, Sismanis A, Tzonou A, Seggas I. Intratympanic and systemic steroids for sudden hearing loss. Otol Neurotol 2013;34(4):771-6.

21) Okada M, Hato N, Nishio SY, Kitoh R, Ogawa K, Kanzaki S, et al. The effect of initial treatment on hearing prognosis in idiopathic sudden sensorineural hearing loss: A nationwide survey in Japan. Acta Otolaryngol 2017;137(Suppl 565):S30-3.

22) Kuhn M, Heman-Ackah SE, Shaikh JA, Roehm PC. Sudden sensorineural hearing loss: A review of diagnosis, treatment, and prognosis. Trends Amplif 2011;15(3):91-105.

23) Lee HM, Oh SJ, Kong SK, Lee IW, Goh EK, Chon KM. Idiopathic sudden sensorineural hearing loss on the only hearing ear. J Clinical Otolaryngol 2016;27(1):84-91.

24) Kang WS, Yang CJ, Shim M, Song CI, Kim TS, Lim HW, et al. Prognostic factors for recovery from sudden sensorineural hearing loss: A retrospective study. J Audiol Otol 2017;21(1):9-15.

25) Park SC, Noh KJ, Lee YJ, Han SJ, Choi HS. Hearing outcome according to the timing of intratympanic dexamethasone injection in idiopathic sudden sensorineural hearing loss. Korean J Otorhinolaryngol-Head Neck Surg 2013;56(1):19-22.

26) Suzuki H, Wakasugi T, Kitamura T, Koizumi H, Do BH, Ohbuchi T. Comparison of 2 and 4 intratympanic steroid injections in the treatment of idiopathic sudden sensorineural hearing loss. Ann Otol Rhinol Laryngol 2018;127(4):235-40.

27) Sugihara EM, Evans MA, Neumann M, Babu SC. The effect of intratympanic steroid injection frequency in idiopathic sudden sensorineural hearing loss. Am J Otolaryngol 2018;39(6):688-92.

28) Wu HP, Chou YF, Yu SH, Wang CP, Hsu CJ, Chen PR. Intratympanic steroid injections as a salvage treatment for sudden sensorineural hearing loss: A randomized, double-blind, placebocontrolled study. Otol Neurotol 2011;32(5):774-9.

29) Li H, Feng G, Wang H, Feng Y. Intratympanic steroid therapy as a salvage treatment for sudden sensorineural hearing loss after failure of conventional therapy: A meta-analysis of randomized, controlled trials. Clin Ther 2015;37(1):178-87.

30) Lee KH, Ryu SH, Lee HM, Park SK, Kim HJ, Chang J. Is intratympanic dexamathasone injection effective for the treatment of idiopathic sudden sensorineural hearing loss? J Audiol Otol 2015;19(3):154-8 